\title{
Effect of quick lime on physicochemical properties of clay soil
}

\author{
Mohammed Mustapha BESSAIM ${ }^{1,3}$, Aicha BESSAIM ${ }^{2}$, Hanifi MISSOUM ${ }^{1,3}$, Karim BENDANI $^{1,3}$ \\ ${ }^{1}$ University Abdelhamid Ibn Badis, Civil Engineering and Architecture Department, Mostaganem, Algeria \\ ${ }^{2}$ University Mustapha Stambouli, Civil Engineering Department, Mascara, Algeria \\ ${ }^{3}$ Construction, Transport and Protection of Environment Laboratory
}

\begin{abstract}
Clay soils are known for their water sensitivity, which causes irreparable damage to any structure built on this type of soil. In order to avoid such problem, it is necessary to use various improvement and stabilization methods such as treatment with lime. This process has been used successfully in the field for decades. The addition of lime generates various physicochemical reactions within the soil such as cation exchange and pozzolanic reactions which are largely responsible for the improvement of the soil in question. This paper presents a study concerning the variation of physicochemical properties of clayey soil with the addition of quicklime at different percentages. Experiments were performed on two clayey soils (CL type) in order to investigate the influence of quicklime on Atterberg limits and $\mathrm{pH}$. These tests were carried out in an attempt to study and follow the development and progression of various reactions occurred within the soil with various lime percentages. The results show that the addition of quicklime causes a significant improvement in soil properties by reducing plasticity and thereby improves the soil workability. It can also be found that the addition of lime increase $\mathrm{pH}$ of soil, which allow activating pozzolanic reactions who tend to stabilize the soil in question by formation of cementitious compounds. Finally, the $\mathrm{pH}$ can be considered as a relevant parameter who allows a better understanding of the reactions that occur in the soil matrix.
\end{abstract}

Keywords: Soil; Quicklime; Chemical reactions; Consistency limits; pH.

\section{Introduction}

Clayey soils have undesirable properties such as low bearing capacity, high compressibility and dispersive behavior. Such properties cause several damage on construction built on this type of soil. Hence, these soils must be treated prior to construction operations, so that desired properties can be achieved [1]. In this regard, improvement methods must be used in order to remedy such problems. Various treatment techniques exist which aim to enhance and stabilize the soil properties. Among these improvement methods, there is treatment with the addition of cementing agents such as lime. This remediation mode is often used. On the one hand, because of its facility and economic appearance and on the other hand due to its effectiveness who allow to obtain engineering materials having superior properties [2-6]. Several studies on the basic lime-clay-reaction mechanisms have been widely reported in literature [7-10] allowing a better understanding of the physicochemical evolution of the system and micro structural features induced after the addition of lime [11-15].

The addition of quicklime $(\mathrm{CaO})$ leads to a modification in the pore fluid chemistry. The first reaction taking place is hydration reaction, highly exothermic, leading to the formation of hydrated lime in the clay water system. The dissociation reaction of the hydrated lime formed due to the quicklime hydration leads to an increase of the $\mathrm{pH}$ and to a high concentration of calcium ions in the pore water [15]. These phenomena cause several reactions in the soil matrix, creating a cation exchange effect and pozzolanic reactions [16]. Firstly, cation exchange lead to a reduction of the thickness of the double layer surrounding clay particles due to calcium ions released from lime that tend to replace the exchangeable cations from clay [17], which also permits to stabilize the clay particles causing an improvement of soil characteristics such plasticity and compaction parameters [18]. Moreover, this exchange causes clay minerals flocculate and agglomerate leading to a quick change in plasticity, workability and particle 
size distribution. In addition to cationic exchange, the high $\mathrm{pH}$ environment induced by lime enables the dissolution of the alumino-silicate constituents of clay minerals, promoting the development of the pozzolanic reactions [15]. These reactions result in the formation of calcium silicate hydrate $(\mathrm{CSH})$, calcium aluminate hydrate $(\mathrm{CAH})$, and calcium alumino silicate hydrate (CASH) gels [19,20]. These amorphous phases crystallise with time, causing the formation of cementitious compounds bonding clay particles together [21-24]. Similarly, this reaction will lead to decrease of liquid limit, plasticity index, and swelling potential of clay [25-28]. However, all of these interactions are highly dependent on $\mathrm{pH}$ of soil. The presence of a high $\mathrm{pH}$ environment, namely $\mathrm{pH}$ value of $12.4-12.6$ (the $\mathrm{pH}$ of a saturated lime solution) or higher, is essential to guarantee the effectiveness of lime $(\mathrm{CaO})$ stabilisation of clays by means of pozzolanic reactions. Thus, as long as the lime is available in the system and the $\mathrm{pH}$ remains high enough to maintain the solubility, pozzolanic reactions continue over time to form bonding compounds that cause long-term strength increase [16-32].

The current study investigated the effect of quicklime on the physicochemical properties of two clayey soils. In the first hand we studied the effect of quicklime in the consistency limits of this soil; on the other hand, we studied the influence of this binder in the variation of the $\mathrm{pH}$ of the soil. Comprehension of this parameter is crucial because it governs the various reactions which are responsible for soil modification and improvement. So this may help to better understand the interactions occurring within the soil matrix.

\section{Materials and experimental methods}

\subsection{Materials}

The soils used in this study soil are residual soils. The studied soils were collected at a depth of about 0.5 to $1 \mathrm{~m}$, where the first soil was a light green and the second was brown in color. The both (soil 1 and 2) are normally consolidated. After that, the soils were excavated, placed in plastic bags and transported to the laboratory for identification and preparation testing. Extreme precautions were taken during sampling to keep the clay in its natural conditions. Table 1 gives a summary of the geotechnical properties of the soils. The soils can be classified as the clay with low plasticity (CL) according to the Unified Classification System (USCS).

\subsection{Lime}

The used lime for this study is quicklime $(\mathrm{CaO})$. Table 2 shows the physicochemical properties of the lime. These results show that the lime used in this study contains a high amount of quicklime $(\mathrm{CaO})$, which confirms the purity of the tested lime.

\subsection{Samples preparation}

In this study, a number of specimens from the clay samples were investigated. To study the influence of lime on physicochemical properties of these soils, quicklime was added to each specimen at room temperature. Initially, all materials were dried thoroughly and then sieved through a \#40 sieve. Then, the quicklime was thoroughly mixed until homogeneity was reached. Distilled water was used in all tests. The amount of soiladmixture was ranging from $0 \%$ to $8 \%$ of quicklime. This established mixture aim to investigate the effects of lime on Atterberg limits and the $\mathrm{pH}$ of the samples.

\subsection{Laboratory tests}

The experiments conducted in the present study include Atterberg limits and $\mathrm{pH}$ test.

\subsubsection{Consistency limits tests}

The Atterberg limit test was performed on the non treated and treated soil samples with different amount of quicklime. From these tests, the effects of lime on the consistency limits of samples were studied. Atterberg limits test was determined in accordance with [33].

\subsection{2 $\mathrm{pH}$ measurements}

The $\mathrm{pH}$ tests were determined using a combined glass electrode, the apparatus has been calibrated for each test using standard solution and preparation of specimens as well as the measurement has been done at room temperature according to [36].

Table 1. Basic properties of the tested soils

\begin{tabular}{|c|c|c|}
\hline Properties & Soil 1 & Soil 2 \\
\hline Soil color & Green & Brown \\
\hline Water content (\%) & 16 & 7.8 \\
\hline Liquid limit (\%) & 42 & 34 \\
\hline Plastic limit (\%) & 21 & 18 \\
\hline Plastic index (\%) & 21 & 16 \\
\hline Specific gravity & 2.70 & 2.65 \\
\hline pd max (Mg/m3) & 1.80 & 1.72 \\
\hline O.M.C (\%) & 14 & 22 \\
\hline Sand (\%) & 12 & 8 \\
\hline Silt (\%) & 48 & 67 \\
\hline Clay (\%) & 40 & 25 \\
\hline $\begin{array}{c}\text { Soil classification } \\
\text { (USCS) }\end{array}$ & CL & CL \\
\hline pH & 8.9 & 8.4 \\
\hline
\end{tabular}


Table 2. Properties of quicklime

\begin{tabular}{|c|c|}
\hline Properties & Values \\
\hline Physical properties & \\
\hline Bulk density $(\mathrm{g} / \mathrm{l})$ & $600-900$ \\
\hline Over $630 \mu(\%)$ & 0 \\
\hline Over $90 \mu(\%)$ & $<10$ \\
\hline Chemical properties (\%) & \\
\hline $\mathrm{CaO}$ & $>83.30$ \\
\hline $\mathrm{MgO}$ & $<0.50$ \\
\hline $\mathrm{Fe}_{2} \mathrm{O}_{3}$ & $<2.00$ \\
\hline $\mathrm{Al}_{2} \mathrm{O}_{3}$ & $<1.50$ \\
\hline $\mathrm{SiO}_{2}$ & $<2.50$ \\
\hline $\mathrm{SO}_{3}$ & $<0.50$ \\
\hline $\mathrm{Na}_{2} \mathrm{O}+\mathrm{K}_{2} \mathrm{O}$ & $0.4-0.5$ \\
\hline $\mathrm{CO}_{2}$ & $<5.00$ \\
\hline $\mathrm{CaCO}_{3}$ & $<10.00$ \\
\hline Insoluble in $\mathrm{HCl}$ & $<1.00$ \\
\hline
\end{tabular}

\section{Results and discussion}

\subsection{Effect of quicklime on Atterberg limits of soil samples}

In order to investigate the effect of quicklime on the consistency limits, measures of liquid and plastic limits were carried out on soil samples at different percentages ranging from $0 \%$ to $8 \%$. The results are shown in Fig. 1. The results showed that there is a slight increase in liquid and plastic limit at $2 \%$ of lime and thereafter both limits start to decrease for the both, soil 1 and 2. This increase in consistency limits can be explained due to a flocculation of soil particles after adding lime. In this phenomenon, the clay particles tend to agglomerate which tend to create bigger aggregates. These latter, have the ability to retain water within the flocculated structure which leads to an increase in the water content. The same result has also been reported by [34,35]. However, increasing lime percent more than $2 \%$ leads to decrease the liquid limit with an increase of plasticity for the two treated samples. The reason of such behavior can be explained by cation exchange, where calcium ions released from the addition of lime which tends to replace other cations around the clay particle surface leading to reducing the thickness of the double layer. Following these results, plasticity index undergoes a relatively large decrease of about $15 \%$ with $8 \%$ lime as shown in Fig.1.a. For the second soil, the plasticity index decrease from $16 \%$ to $10.5 \%$ with the same lime content as represented in Fig.1.b. These results are in agreement with those published by [16]. Phenomena such cation exchange and flocculation occur shortly after adding the lime which generate a decrease in the soil plasticity [37-40]. Furthermore, the reduction in plasticity can be attributed to the increasingly granular nature of the lime treated clay soil induced by the short term reactions (cation exchange and flocculation-agglomeration). Moreover, the lime addition causes a significant improvement in soil properties by reducing plasticity and eliminating swelling [16].
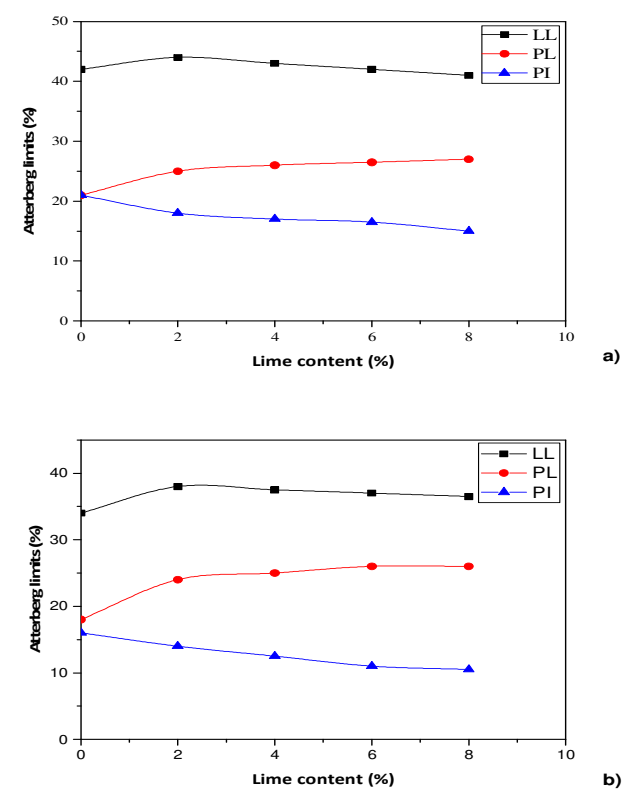

Fig. 1. Atterberg limits of lime-treated samples: a) Soil 1, b) Soil 2 .

\subsection{Effect of lime on pH of soils samples}

Fig. 2 shows the variation of $\mathrm{pH}$ with the percentage of added lime in a range of $(0$ to $8 \%)$. In the soil 1 , the natural $\mathrm{pH}$ is estimated to 8.9. As can be seen, the $\mathrm{pH}$ value rises rapidly to 11.9 with $2 \%$ lime. Then, there is an increase of $\mathrm{pH}$ value until reaches 12.5 with the lime percentage of $4 \%$. After that, the $\mathrm{pH}$ value increases slowly to reach a constant value equal to 12.6 with $8 \%$ lime as show in Fig.2.a. However, a tiny effect of lime addition above $4 \%$ is noted in term of $\mathrm{pH}$. The same results were observed in the soil 2 , where the initial value of $\mathrm{pH}$ soil is 8.4 . With $2 \%$ lime, the $\mathrm{pH}$ of quicklime-soil mixture reached 11.7 and increased to about 12.4 with lime percentage of $4 \%$. After that, a lower increase of $\mathrm{pH}$ until remained constant value of 12.5 with $8 \%$ as presented in Fig.2.b. The same behavior has been seen by [16] and it in accord with our results. As can be seen the "lime fixation point" was reached by $4 \%$ lime for the two soils. These results are in agreement with the results of several researchers [16,41]. According to [41] a $\mathrm{pH}$ of 12.4 is the optimum value or the lime fixation point how allows activating the pozzolanic reaction, according to $\mathrm{pH}$ measurements. The increase of $\mathrm{pH}$ value can be explained to a variation in the pore fluid chemistry following the addition of quicklime. Firstly, there is the hydration reaction of quicklime, highly exothermic (allow to reduce the water content), leading to the formation of hydrated lime $\left(\mathrm{Ca}(\mathrm{OH})_{2}\right)$ in the clay water system as follow [42]:

$$
\begin{aligned}
& \mathrm{CaO}+\mathrm{H}_{2} \mathrm{O} \rightarrow \mathrm{Ca}\left(\mathrm{OH}_{2}\right)+\mathrm{Heat}(\Delta) \\
& \mathrm{Ca}(\mathrm{OH})_{2} \rightarrow \mathrm{Ca}^{2+}+2(\mathrm{OH})^{-}
\end{aligned}
$$

The dissociation reaction of the hydrated lime formed due to the quicklime hydration leads to an increase of the $\mathrm{pH}$ and to a high concentration of calcium ions in the pore 
water [15]. This high $\mathrm{pH}$ leads the dissolution of the silica and the alumina released from clay minerals, which react with lime (combination with the calcium) creating new cementitious compounds such as calcium silicate hydrates $(\mathrm{CSH})$, calcium aluminate hydrates $(\mathrm{CAH})$ and calcium alumino-silicate hydrates (CASH) as shown in the following equations [42]:

$$
\begin{aligned}
& \mathrm{Ca}^{2+}+2(\mathrm{OH})^{-}+\mathrm{SiO}_{2} \rightarrow \mathrm{CSH} \\
& \mathrm{Ca}^{2+}+2(\mathrm{OH})^{-}+\mathrm{Al}_{2} \mathrm{O}_{3} \rightarrow \mathrm{CAH}
\end{aligned}
$$

This high alkalinity environment $(\mathrm{pH}=12.4)$ produced by the addition of lime allows activating pozzolanic reaction. Maintaining this rate is essential to guarantee the effectiveness of quicklime $(\mathrm{CaO})$ stabilization of clays by means of pozzolanic reactions [15]. These latter allow to bind soil particles together and result in the improvement of the soil properties [23, 24].
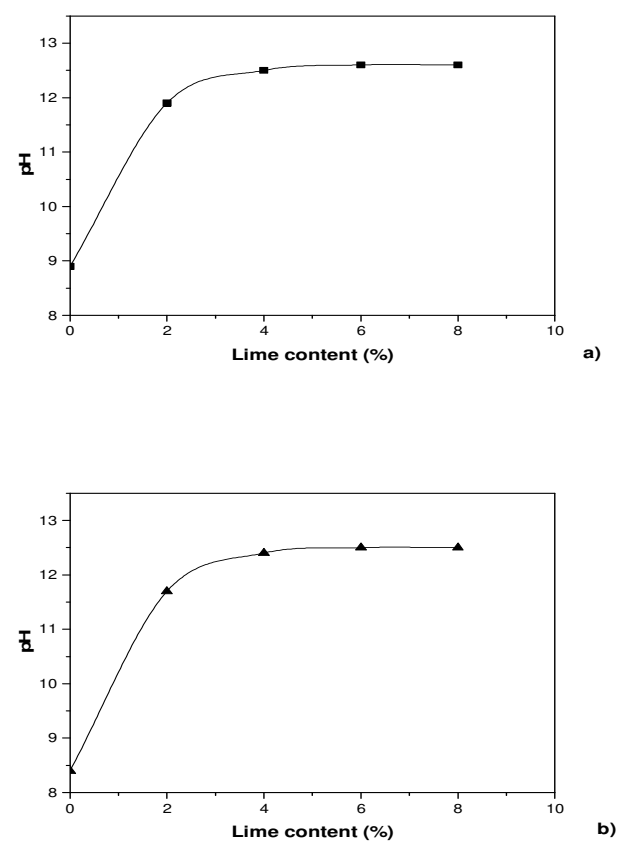

Fig. 2. pH values of lime-soil mixtures: a) Soil 1, b) Soil 2.

\section{Conclusion}

A laboratory investigation was undertaken to study the effect of quicklime on physicochemical properties of two clayey soils (CL type). The main findings allow the following conclusions to be drawn:

The addition of quicklime in clayey soils leads to a significant modification in soil properties with reducing plasticity and thereby improving the soil workability.

The lime addition increase $\mathrm{pH}$ of the soil due to the dissociation reaction of the hydrated lime formed by the quicklime hydration.

The addition of quicklime reduces plasticity index and increase the $\mathrm{pH}$. This is in agreement with the results of most of the researchers.
The change in soil behavior (decrease in plasticity and an increase in $\mathrm{pH}$ ) is directly linked to the reactions and to the change of pore fluid chemistry of the medium following the addition of quicklime.

The $\mathrm{pH}$ is a relevant parameter that allows a better understanding and can be used to study and follow the development and progression of various reactions such as cation exchange and pozzolanic reactions.

A percentage of $4 \%$ lime was found sufficient to reach the lime fixation point.

The high $\mathrm{pH}$ is essential to activate pozzolanic reactions for the formation of the cementitious compounds and thereby improving soil properties.

To guarantee the effectiveness of quicklime stabilization of the clayey soils, a $\mathrm{pH}$ above or equal to lime fixation point value is primordial.

\section{References}

1. K.A. Saeed, K.A. Kassim, H. Nur., Physicochemical characterization of cement treated kaolin clay. Gradevinar, 66, 513-521 (2014).

2. D. Castro-Fresno, D. Movilla-Quesada, A. VegaZamanillo, M.A. Calzada-Pérez., Lime stabilization of bentonite sludge for tunnel boring. Appl. Clay Sci. 51, 250-257 (2011).

3. M. Di Sante, E. Fratalocchi, F. Mazzieri, E. Pasqualini., Time of reaction in a lime treated clayey soil and influence of curing conditions on its microstructure and behaviour. Appl. Clay Sci. 99, 100-109 (2014).

4. S.Z. George, D.A. Ponniah, J.A. Little., Effect of temperature on lime-soil stabilization. Constr. Build. Mater. 6, 247-252 (1992).

5. S. Kolias, V. Kasselouri-Rigopoulou, A. Karahalios., Stabilization of clayey soils with high calcium fly ash and cement. Cem. Concr. Compos. 27, 301-313 (2005).

6. A. Modarres, Y.M. Nosoudy., Clay stabilization using coal waste and lime-Technical and environmental impact. Appl. Clay Sci. 116-117, 281-288 (2015).

7. J.L Eades, R.E. Grim., Reactions of hydrated lime with pure clay minerals in soil stabilization. Highw. Res. Board Bull. 262, 51-53 (1960).

8. E. Pomakhina, D. Deneele, A.C. Gaillot, M. Paris, G. Ouvrard., 29Si solid state NMR investigation of pozzolanic reaction occurring in lime treated $\mathrm{Ca}$ bentonite. Cem. Concr. Res. 14, 626-632 (2012).

9. L. Dewindt, D. Deneele, N. Maubec., Kinetics of lime/bentonite pozzolanic reactions at 20 and $50^{\circ} \mathrm{C}$ : batch tests and modeling. Cem. Concr. Res. 59, 34$42(2014)$.

10. Y.C. Chemeda, D. Deneele, G.E. Christidis, G. Ouvrard., Influence of hydrated lime on the surface properties and interaction of kaolinite particles. Appl. Clay Sci. 107, 1-13 (2015).

11. G. Russo, S. Dal Vecchio, G. Mascolo., Microstructure of a lime stabilised compacted Silt. In: Schanza, Dans In T. (Ed.), Experimental 
Unsaturated Soil Mechanics. Springer, Berlin Heidelberg, pp. 49-56 (2007).

12. Z. Metelkova, J. Bohac, R. Prikryl, I. Sedlarova., Maturation of loess treated with variable lime admixture: pore space textural evolution and related phase changes. Appl. Clay Sci. 61, 37-43 (2012).

13. G. Russo, G. Modoni., Fabric changes induced by lime addition on a compacted alluvial soil. Geotechnique Lett. 3, 93-99 (2013).

14. E. Vitale, D. Deneele, G. Russo., Multiscale analysis on the behaviour of a lime treated bentonite, VI Italian Conference of Researchers in Geotechnical Engineering-Geotechnical Engineering in Multidisciplinary Research: from Microscale to Regional Scale, CNRIG2016. Procedia Eng. 158, 87-91(2016).

15. E. Vitale, D. Deneele, M. Paris, G. Russo., Multiscale analysis and time evolution of pozzolanic activity of lime treated clays. Applied Clay Science, 141, 36-45 (2017).

16. M. Al Mukhtar, A. Lasledj, J.F, Alcover., Behavior and mineralogy changes in lime treated expansive soil at $20{ }^{\circ} \mathrm{C}$. Applied Clay Science, 50, 191-198 (2010).

17. C.D. Rogers, S. Glendinning., Modification of clay soils using lime. In: CDF Rogers, Dans S.G. (Ed.), Lime Stabilisation. Thomas Telford, London, pp. 99-112 (1996).

18. S. Leroueil, J.P Le Bihan., Liquid limits and falling cones. Can. Geotech. J. 33, 793-798 (1996).

19. J.K. Mitchell., Practical problems from surprising soil behaviour. J. Geotech. Eng., ASCE 112, 259289 (1986).

20. J.B. Croft., The pozzolanic reactivates of some New South Wales fly ashes and their application to soil stabilization. Proc. ARRB, Australia 2, 144-167 (1964)

21. O.G. Ingles, J.B. Metcalf., Soil Stabilisation: Principles and Practice. Butterworths, Sidney, Australia (1972).

22. F.G. Bell., Lime stabilisation of clay minerals and soils. Eng. Geol. 42, 223-237 (1996).

23. D.N. Little., Fundamentals of the Stabilization of Soil With Lime: National Lime Association. Bulletin vol. 332. Arlington, USA, pp. 1-20 (1996).

24. R. James, A.H. Kamruzzaman, A. Haque, A. Wilkinson., Behaviour of lime-slag-treated clay. Proceedings of the ICE-Ground Improv. vol. 161 (4), pp. 207-216 (2008).

25. M. Khemissa, A. Mahamedi., Cement and lime mixture stabilization of an expansive overconsolidated clay. Appl. Clay Sci. 95, 104-110 (2014).

26. A.R. Goodarzi, M. Salimi., Stabilization treatment of a dispersive clayey soil using granulated blast furnace slag and basic oxygen furnace slag. Appl. Clay Sci. 108, 61-69 (2015).

27. J.M. Kinuthia, S. Wild., Effects of some metal sulphates on the strength and swelling properties of lime-stabilised kaolinite. Int. J. Pavement Eng. 2 (2), 103-120 (2001).
28. R.W. Grimshaw., The Chemistry and Physics of Clays. Fourth Editing. Ernest Benn (1971).

29. J. Locat, H. Tremblay, S. Leroueil., Mechanical and hydraulic behaviour of a soft inorganic clay treated with lime. Can. Geotech. J. 33 (4), 654-669 (1996).

30. P.V. Sivapullaiah, A. Sridharan, A.N. Ramesh., Strength behaviour of lime treated soils in the presence of sulphate. Can. Geotech. J. 37, 13581367 (2000).

31. H. Tremblay, S. Leroueil, J. Locat., Mechanical improvement and vertical yield stress prediction of clayey soil from eastern Canada treated with lime or cement. Can. Geotech. J. 38, 567-579 (2001).

32. S.M. Rao, P. Shivananda., Role of curing temperature in progress of lime-soil reactions. Geotech. Geol. Eng. 23 (1), 79-85 (2005).

33. ASTM D-4318., Standard test method for liquid limit, plastic limit and plasticity index of soils. Annual Book of ASTM Standards, vol. 04.08. Easton, PA: American Society for Testing and Materials (2000).

34. J. Locat, H. Tremblay, S. Lerouil., "Mechanical and hydraulic behavior of a soft inorganic clay treated with lime". Journal of Geotechnical 33, 654-669 (1966).

35. S.H. Chew, A.H.M. Kamruzzaman, F.H. Lee, "Physicochemical and engineering behavior of cement treated clayey". Journal of Geotechnical and Geo-Environmental Engineering 130, 696-706 (2004).

36. R.C. Bates., Electrometric pH determination, John Wiley and sons Inc. New York (1954).

37. B. Le Runigo, O. Cuisinier, Y.J. Cui, V. Ferber, D. Deneele., Impact of initial state on the fabric and permeability of a lime-treated silt under long-term leaching. Canadian Geotechnical Journal, 46, 1243 1257 (2009).

38. T. Umesha, S. Dinesh, P. Sivapullaiah., Control of dispersivity of soil using lime and cement. International Journal of Geology, 3, 8-16 (2009).

39. J.C. Dong., Investigation of aggregates size effect on the stiffness of lime and/or cement treated soils: From laboratory to field conditions (Ph.D thesis). Université Paris Est, France (2013).

40. S.A. Bourokba, A. Hachichi, H. Souli, S. Taibi, J.M. Fleureau., Effect of lime on some physical parameters of a natural expansive clay from Algeria, European Journal of Environmental and Civil Engineering (2015).

41. J.L. Eades, R.E. Grim., A quick test to determine lime requirements for lime stabilization. Highw. Res 139: 61-72 (1966).

42. J.M. Kinuthia, S. Wild, G.I. Jones., Effects of monovalent and divalent metal sulphates on consistency and compaction of lime-stabilized kaolinite. Appl. Clay Sci. 14, 27-45 (1999). 